\title{
Q̈FORSETI
}

Forseti. Revista de Derecho. Volumen 11, No 15, Lima, 2022, pp. 50 - 62

\section{Responsabilidad penal del socio fundador por conductas delictivas de los administradores}

\author{
Sergio Valdivia Reyes*
}

Resumen. - El presente artículo aborda la posible responsabilidad penal del socio fundador por conductas delictivas de los administradores en el ejercicio de la actividad empresarial, resaltando la diferencia existente entre el socio fundador y el administrador de la persona jurídica. Asimismo, se denotan los lineamientos que se deben tener en cuenta para analizar una posible imputación de responsabilidad al socio fundador, debiéndose enmarcar su conducta en dos momentos: i) el socio como fundador de la empresa y ii) el socio fundador en el funcionamiento de la empresa.

\begin{abstract}
This article addresses the possible criminal liability of the founding partner for criminal conduct of administrators in the exercise of business activity, highlighting the difference between the founding partner and the administrator of the legal entity. Likewise, the guidelines that must be considered to analyze a possible imputation of responsibility to the founding partner are denoted, and their conduct must be framed in two moments: i) the partner as founder of the company y ii) the founding partner in the operation of the company.
\end{abstract}

Palabras claves. - Socio fundador, administrador, posición de garante, deberes residuales, esferas de competencia.

Keywords. - Founding partner, administrator, guarantor position, residual duties, spheres of competence.

* Bachiller en Derecho por la Facultad de Derecho y Ciencia Política de la Universidad Nacional Mayor de San Marcos. Asistente de Cátedra de Derecho Penal Económico y de la Empresa de la misma casa de estudios. Miembro Principal del Taller Dogmática PenalUNMSM-. 
"El novelista delega en personajes imaginarios los pecados que él tiene la prudencia de no cometer".

Anthony Burgess ${ }^{1}$

\section{Introducción}

En la actualidad el Derecho Penal, en específico, el Derecho Penal Económico, debe hacer frente a nuevos y complejos problemas, en especial, a los delitos cometidos a través de estructuras organizadas complejas como la empresa, la misma que se rige por los principios de división funcional del trabajo y de jerarquía. Así, cuando una empresa está inmersa en delitos cometidos a raíz de su actividad empresarial -más allá de lo sostenido que la empresa como organización pueda responder por un injusto propio- se tiende a individualizar a los posibles autores o partícipes de esta, fijando la mirada a los órganos de administración de la misma (modelo top dow $^{2}$ ). Pero, muchas veces, también se atribuye la responsabilidad penal a aquellas personas que dieron origen a la persona jurídica; es decir, a los socios fundadores.

En el presente trabajo se dilucidará la posible responsabilidad penal del socio fundador por conductas delictivas de los administradores en el ejercicio de la actividad empresarial (delito desde la empresa3), centrándonos por lo tanto en la figura de aquella persona natural que dio origen a la persona jurídica, pero no tiene la gestión administrativa de esta. Resulta menester indicar que, acorde a la moderna complejidad empresarial, puede presentarse la figura del socio fundador también como administrador de la persona jurídica que ha formado, y que pese a no estar propiamente reconocido en el estatuto u normativa interna como miembro del órgano de administración, funge dichas funciones; por ello, consideramos que de presentarse tal contexto, para evaluar la posible responsabilidad penal, podríamos hacer uso de lo desarrollado para la figura del administrador de hecho. Siendo así, conlleva una mayor complejidad pretender atribuir alguna responsabilidad penal a aquella persona que ha dado origen a la actividad empresarial, pero que no la administra. La teoría ha recurrido a la figura de la posición de garante para brindar un criterio de imputación y evitar posibles impunidades, atribuyendo al socio fundador un deber de garante para con la actividad empresarial, delegando estos deberes a los administradores de la sociedad, por lo que, si estos cometiesen algún delito como parte de la actividad empresarial, los socios fundadores responderían también por este ilícito debido a la omisión del cumplimiento de una manera adecuada de sus deberes.

1 BURGESS, Antony. La naranja mecánica. 1962 (primera edición), p. 8

2 Modelo de imputación en el cual se atribuye la responsabilidad a los miembros de mayor "jerarquía" (administradores), a diferencia del modelo bottom up, en el cual se atribuye la responsabilidad penal a los de menor "rango" (operarios, trabajadores de planta).

3 "Desde la empresa" son delitos que la empresa realiza en el desarrollo de su actividad social, en contraposición de los delitos "dentro de la empresa" que son delitos cometidos por los órganos de la empresa contra otros órganos o contra la empresa misma. 
Atendiendo al objeto del presente, asentaremos postura sobre si efectivamente los socios son garantes -originarios- de la actividad empresarial y lo que traería consigo aceptar dicho criterio, esto es, socio fundador penalmente responsable al omitir deberes residuales. También, esbozaremos lineamientos sobre en qué momento el socio fundador podría responder penalmente por algún delito cometido desde la empresa por los administradores.

\section{Propiedad y control de la empresa}

En la actualidad, la complejidad de las interacciones sociales -y con ello el mayor desarrollo del fenómeno empresarial- ha relegado la clásica concepción del empresario como dueño y gestor total de una empresa. Esto último puede ser de recibo aún en aquellas formas empresariales pequeñas en cuanto a su organización, por el número de personas, el capital que lo conforman y el objeto social, lo cual permite al socio-gestor materialmente tener el dominio del funcionamiento de su empresa. Empero, ello no es posible en la mayoría de las formas empresariales, debido a la complejidad que demanda el desarrollo del objeto social de la empresa y con ello la especialización funcional que se necesita, la división del trabajo y la necesaria participación de varias personas. Por lo que, para una mejor organización y desarrollo de la actividad empresarial, se opta por la división del trabajo por especialidades y/o funciones debidamente limitadas y organizadas, en su mayoría de manera jerarquizada, tanto así que en la estructura organizativa de la empresa se puede apreciar diferentes niveles de jerarquía. Siguiendo a Mintzberg4, es posible distinguir tres partes básicas el ápice estratégico (cúpula directiva), la línea media (cadena de directivos con autoridad formal que sirven de enlace entre la directiva y los trabajadores) y el núcleo de operaciones (operarios que realizan el trabajo fundamental de la organización), no formando parte de esta estructura interna los titulares dueños de la empresa, es decir, los socios fundadores.

Así, coincidiendo con García Cavero, podemos referir que el modelo actual de empresa no es más la empresa individual en la que el propietario asume efectivamente las labores de dirección, sino una empresa en la que los propietarios son solo inversionistas que no entran a tallar en la gestión de esta 5 .

\section{Referencia a la cuestión doctrinal implicada}

\section{i. Deberes originarios y residuales}

Es en atención a la necesidad de protección al desempeño de la alta función pública que el legislador optó por la sustitución de la prerrogativa procesal y no por su supresión. No obstante, tal como va evolucionando el sistema jurídico

4 MINTZBERG, Henry. La estructuración de las organizaciones. Barcelona: Ariel Economía, 1993, pp. 44-55.

5 GARCÍA CAVERO, Percy. Intervención delictiva en estructuras empresariales. Lima: Ideas solución, 2019, p. 171. 
constitucional y su deseo de limitar los potenciales espacios de impunidad o suprimir prerrogativas procesales-penales otorgadas a altos dignatarios, es posible que -en un futuro no muy lejano- incluso la garantía de fuero privilegiado sea eliminada, dando pase a un juzgamiento penal por los tribunales ordinarios de ciertos altos dignatarios por la comisión de delitos sin ejercer la función pública.

En el Derecho penal, las normas pueden agruparse en dos grandes grupos: i) normas prohibitivas, las cuales buscan impedir la realización de una conducta determinada, por lo que la infracción de dicha norma sería la realización de la conducta prohibida; y ii) normas preceptivas, mediante las cuales se exige que el sujeto actúe de una determinada manera, la infracción de estas normas consiste en omitir dicho mandato. En palabras estrictamente profanas, podemos decir que las normas prohibitivas prohíben al sujeto a actuar de cierta manera (ejemplo: no matar) y las normas preceptivas exigen un actuar especifico por parte del agente (ejemplo: prestar auxilio).

En el grupo de las normas preceptivas -que nos son de interés en el presente artículo-, específicamente en lo referido a la omisión impropia, se ubica aquella figura jurídica con la cual se le exige a la persona la evitación de la producción de un resultado penalmente sancionado, considerándole autor o partícipe por su no actuación conforme a la expectativa de conducta. Ello en la doctrina recibe el nombre de posición de garante.

Siguiendo al profesor Hurtado Pozo, podemos referir que la posición de garante tiene la función de determinar entre las personas que pueden evitar, mediante un acto positivo la realización del resultado, aquella que tiene el deber de intervenir para garantizar que este no se produzca. Lo referido resulta, así mismo, útil para imputar, a quién se ha abstenido, el perjuicio que ha afectado al bien jurídico protegido mediante el tipo legal respectivo ${ }^{6}$. Igualmente, es de tener en cuenta que la infracción a los deberes de garante puede presentarse de los modos siguientes: a) deberes de aseguramiento, b) deberes de salvamento y c) deber por asunción ${ }^{7}$. En el primero, este deber es el más general, que alcanza a todas las personas, consiste en que el obligado tiene a su cargo la administración de una fuente de peligro con la responsabilidad de no superar el riesgo permitido y que de esta no se deriven consecuencias lesivas para terceros. En cuanto al deber de salvamento, este se origina si del ámbito de organización de la persona ha salido un peligro que puede alcanzar a un tercero y lesionarlo en sus derechos. En este grupo es donde podemos encontrar lo denominado como "injerencia", así se activa un deber de garante por injerencia para todo aquel que organiza algo peligroso (actuar precedente), debiendo el obligado evitar los daños que resultan de dicha actuación. $\mathrm{Y}$, en lo que respecta al deber por asunción, aquí el obligado, de manera voluntaria

6 HURTADO POZO, José. Manual de Derecho Penal. Parte General I. Lima: Grijley E.I.R.L, 2005, p. 755.

7 CARO JHON, José A. Normativismo e imputación jurídico-penal. Estudios de derecho penal funcionalista. Lima: Ara Editores, 2010, p. 253. 
amplía su competencia asumiendo una obligación de la que no se puede desentender8.

Asimismo, resulta menester tener en cuenta que, la posición de garantía inicial, la competencia originaria, puede ser delegada en otra persona. Esta "delegación" es comprendida como aquella técnica mediante la cual el delegante (quien tiene la posición de garante) se descarga de funciones y competencias iniciales, traspasándolas al delegado, y produciéndose con ello una transformación de esferas de responsabilidad, tanto en el primero como en el segundo9. Se comprende, así, que la delegación de competencias constituye un mecanismo de transferencia y transformación de posiciones de garantía. Transferencia, porque en virtud de la delegación, el delegante hace surgir una posición de garantía en el delegado. Transformación, porque la posición de garantía del delegante no desaparece, sino que se transforma ${ }^{10}$. Con ello, se puede afirmar que con la delegación se ha generado una segunda posición de garante, la misma que recae en el delegado, quien la asume por asunción (voluntad propia) produciéndose en este una ampliación de sus esferas de competencia, teniendo el deber de controlar determinados riesgos. Siendo así, resulta admisible la convivencia de ambas posiciones, tanto del delegado como del delegante: la del delegante como secundaria o residual y la del delegado como primaria.

Así entonces, quien ostentaba originariamente la posición de garante, luego de haber transferido dichos deberes al delegado, ya no le compete el deber de control directo sobre los focos de riesgo que demandaba la posición de garante, sino que ahora el control de dichos focos de riesgo será de competencia del delegado. Pero, es de resaltar aquí que, a pesar de haber transferido los deberes, el garante originario aún posee deberes residuales para con el delegado, tales deberes son: la correcta selección, formación -si fuera precisa- e información del delegado, la dotación a este con los medios necesarios para el cumplimiento de sus funciones; la coordinación de la actuación de diversos delegados, y, sobre todo -al menos es lo que suele indicarse- el deber de vigilancia y control11. Entonces, pese a haberse realizado la delegación de deberes, el delegante retiene aún competencias (deberes residuales), cuya omisión puede incidir en alguna responsabilidad penal, ya sea a título de autor o cómplice de algún delito cometido por el delegado.

8 CARO JHON, José A. Manual teórico práctico de teoría del delito. Lima: Ara Editores, 2014, pp. 235249.

9 RAGUÉS I VALLÈS, Ramon \& ROBLES PLANAS, Ricardo. (Dirs) Delito y empresa. Estudios sobre la Teoría del delito aplicada al Derecho penal económico-empresarial. Barcelona: Atelier, 2018, p. 64.

10 SILVA SÁNCHEZ, José M. Deberes de vigilancia y compliance empresarial. En Fundamentos de Derecho Penal de la empresa. Madrid: Edisofer, 2016, p. 199.

11 Ídem, p. 200. 


\section{ii. Deberes residuales y esferas de competencia}

Con base a lo descrito en líneas anteriores, se puede afirmar que no es de recibo que el delegante confíe plenamente en que el delegado cumplirá las funciones delegadas a su persona, resaltándose aquí que el delegante aún mantiene el deber residual de vigilancia y control, el cual obliga a este a verificar el correcto cumplimiento del delegado para con las funciones que ha asumido por asunción. Esta obligación, basada en los deberes residuales, que tiene el delegado para como el delegante correspondería con el llamado «principio de desconfianza». Trayendo a colación lo referido por Gómez Martín, este principio aludido obliga al delegante a vigilar al delegado, asegurándose de su competencia efectiva, de la suficiencia debidamente actualizada de los medios personales y materiales puestos a su disposición, de la autonomía funcional de su posición, y, finalmente, del correcto desempeño de sus funciones. Siguiendo lo referido por el profesor español, el mencionado principio de desconfianza resultaría aplicable a casos de transferencia de competencias por medio de la delegación de un órgano jerárquicamente superior a otro subordinado ${ }^{12}$. Ello es de plena aplicación en las empresas jerárquicamente organizadas que, como se advirtió, por lo general se estructuran con un ápice estratégico, línea media y un núcleo de operaciones.

Ahora bien, lo referido ut supra, como se recalcó, se aplica en estructuras organizadas jerárquicamente, los superiores como delegantes y los subordinados como delegados. Empero, ello varía si se trata de estructuras cuya relación se basa en la horizontalidad, esto es, donde no exista subordinación alguna, como es el caso de órganos colegiados o áreas determinadas de una empresa (área de marketing con el área de ensamblaje), siendo evidente aquí que las funciones de cada área o sujeto, responden a un criterio de especialización no siendo posible que otros puedan realizar dicha actividad, lo cual nos lleva a concluir que en estructuras horizontales, el criterio de atribución responde a la división funcional del trabajo, lo que se denomina como "esferas de competencia".

Volviendo a la línea argumentativa de Gómez Martín podemos referir que, a diferencia de lo que sucede con el principio de confianza - que impone al superior jerárquico deberes de adquisición de conocimiento e instancia a la corrección en caso se tenga conocimiento de alguna disfunción en la gestión de la actividad delegada - y con el principio de desconfianza - que genera deberes de vigilancia previos sobre la actividad del subordinado - , en el plano de la especialización

12 GÓMEZ MARTÍN Víctor. “Delegación de competencias y compliance penal: un estudio sobre la transferencia y transformación de los deberes (de vigilancia) en el derecho penal económico". En DERECHO PUCP, núm. 85, 2020 diciembre-mayo, pp. 115-138. 
horizontal se parte del presupuesto contrario: cada especialista es responsable de sus propias competencias, que desempeñará con el apoyo de conocimientos, medios y recursos particularmente especializados ${ }^{13}$.

\section{Responsabilidad del socio fundador por conductas delictivas de los administradores}

\section{i. ¿El socio fundador como garante originario de la actividad social?}

Teniendo en cuenta que el presente estudio se encuentra delimitado en la posible responsabilidad penal que podría acarrear el socio fundador por delitos cometidos por los administradores de la empresa bajo el aparente desarrollo del objeto social -delitos cometidos desde la empresa-, resulta de necesidad dilucidar sobre la relación del socio con la actividad empresarial. Entonces, considerando que el socio por decisión propia ha decidido emprender el desarrollo de una actividad social junto a otras personas -demás socios- con el fin de obtener beneficios lucrativos -constitución de la empresa-, ello ha llevado que parte de la doctrina considere al socio como garante originario de los riesgos que puedan emanar de la actividad empresarial a la cual se dedica la empresa creada por este, teniendo así los deberes originarios de garante para luego delegar estos deberes al órgano de administración que se hará cargo del manejo de la empresa.

Lascuraín Sánchez refiere que un emprendedor lo es porque inicia una actividad productiva. Así, el titular de la empresa es garante porque desata riesgos o porque mantiene como propias fuentes de riesgo. Es más -agrega el citado autor- si como sociedad permitimos que se emprendan actividades peligrosas es desde luego el principio de libertad de actuación y por la utilidad social de la empresa, pero también porque imponemos al emprendedor severos deberes de control del riesgo. Y severos significa, aquí, deberes penalmente reforzados, deberes de garante ${ }^{14}$. En similar sentido, Silva Sánchez refiere que la posición de garantía inicial, la competencia originaria, es, pues, del empresario en la medida en que este crea una organización para la producción y distribución de bienes o para la realización de servicios. Esta organización conlleva la asunción del compromiso de que de la misma no resulten hechos lesivos. Tal competencia es, sin embargo, delegable, lo que supone un cambio decisivo de la situación existente ${ }^{15}$.

Una observación que realizamos desde esta palestra está dirigida al uso del

13 GÓMEZ MARTÍN, op., cit., p. 115-138

14 LASCURAÍN SÁNCHEZ, Juan A. "Salvar al oficial Ryan sobre la responsabilidad penal del oficial de cumplimiento". En Responsabilidad de la empresa y compliance. Programas de prevención detección y reacción penal. Mir Puig, S., Corcoy Bidasolo, M y Gómez Martín, V. (Dirs) Madrid: Edisofer, 2014, pp. 314-315.

15 SILVA SÁNCHEZ, José M \& SUÁREZ GONZALES, Carlos J. “La autoría delictiva en estructuras organizadas". En la dogmática penal frente a la criminalidad en la administración pública y otros problemas actuales del derecho penal. Lima: Grijley, 2001, p. 16. 
término "empresario", ello debido a que los autores al momento de pretender delimitar la responsabilidad penal del "empresario" hacen referencia al miembro del órgano de Administración (administrador o en su caso gerente) de una empresa como la persona que ha dado origen a esta persona jurídica, sin distingo alguno entre socio fundador y gerente y/o administrador. Esto es, equiparan al socio fundador de la empresa con aquella persona que dirige y tiene el control de la misma, gerente general o administrador. Como se ha indicado, desde esta perspectiva, consideramos que en la mayoría de las empresas podemos encontrar aquellas personas que han fundado la empresa y por sus aportes se mantiene en funcionamiento -socios- y aquellas personas que tienen el control propiamente del funcionamiento de la empresa -órganos de administración-. Por lo que, consideramos que al momento de usar el término "empresario" es menester realizar la diferencia a quién específicamente nos estamos refiriendo, si al socio fundador o a aquella persona que administra propiamente el correcto funcionamiento de esta persona jurídica.

En el presente trabajo pretendemos analizar la posible responsabilidad penal del socio fundador de la empresa por delitos cometidos por los órganos de administración, para lo cual no compartimos que el socio fundador de la persona jurídica tenga deberes de garante para con los órganos de administración por el desarrollo de la actividad empresarial. En líneas posteriores fundamentaremos esta posición. Previo a ello, haremos referencia a dos tesis, la primera sostiene que el socio fundador es el garante originario de la actividad empresarial, por lo que, si estos los delega, retendría aún deberes residuales. La segunda el socio fundador es garante originario y tiene esferas de competencia para con los delegados.

\section{ii. Primera tesis: socio fundador como garante originario con deberes residuales}

Antes de la reforma constitucional, el procesamiento del alto dignatario al que se levantaba la inmunidad correspondía a un fuero ordinario, siguiendo las reglas previstas en el Código procesal penal de 2004 o del Código de procedimientos penales de 1939. No obstante, la reforma constitucional en comentario cambia radicalmente el supuesto anterior y establece un sistema diferenciado. Para los casos donde la imputación sea el cometer un delito sin ejercicio de la función pública (delitos comunes), los cuales fueran imputados con anterioridad al ejercicio de la función del alto dignatario, la reforma constitucional ha previsto que el procesamiento siga a cargo de un juez penal ordinario. Para los casos en los que la imputación surja cuando el alto dignatario se encuentre en ejercicio del cargo, por hechos sin ejercer la función pública, la competencia del procesamiento la tendrá la Corte Suprema de la República.

Para atribuir alguna responsabilidad penal al socio fundador de una empresa se ha recurrido a criterios de imputación con base en la posición de garante que - 
acorde a la doctrina mayoritaria- tiene el "empresario" que ha dado origen a la persona jurídica (para nosotros socio fundador), es decir, se le atribuye que ostenta deberes de garantía debido a su actuar precedente al resultado, esto es, por injerencia.

Como bien se ha referido el acto de delegación da origen a una nueva posición de garantía la cual recae sobre los delegados, empero esta delegación no extingue la posición de garantía que ostentaba el delegante quedando con él una posición de responsabilidad residual, esto es, aún mantiene algunas competencias, como por ejemplo el deber de vigilancia y control.

Así entonces, una primera tesis que se sostiene con base en el socio fundador como garante de la actividad empresarial, es que 2este delega en el administrador o administradores el control de la actividad empresarial, en otras palabras, que mantenga dentro de los márgenes del riesgo permitido o de ser el caso disminuir las consecuencias negativas para terceros que pudiera haber ocasionado la fuente de riesgo. Siendo la empresa y su actividad empresarial la fuente de peligro o de riesgo. Teniéndose el binomio siguiente: socio como delegante y administrador como delegado. Pero, atendiendo que la delegación no conlleva a un deslinde total de las competencias, el socio fundador tendría consigo deberes residuales que lo lleva asumir alguna responsabilidad penal cuando este ha omitido el cumplimiento de estos deberes residuales basado también en el principio de desconfianza, el mismo que exige al delegante (superior) no confiar plenamente en que el delegado (subordinado) cumplirá adecuadamente las funciones atribuidas. Citando ejemplos -acorde la presente tesis- tendrá responsabilidad penal aquel socio fundador por algún delito cometido desde la empresa por el administrador cuando el primero de estos haya nombrado en el puesto administrador aquella persona inidónea para asumir el cargo, o también, cuando el socio se desentiende de aquel deber residual de vigilar y controlar que el administrador desarrolle adecuadamente las funciones que se le ha encomendado, y producto de esa omisión ha llevado que el administrador pueda haber realizado una serie de delitos.

\section{iii. Segunda tesis: socio fundador como garante originario y esferas de competencia}

Una segunda tesis que parte del socio fundador como garante originario de la actividad empresarial, sustenta que la relación que existe entre socio y administrador no es la de delegante y delegado, esto es superior y subordinado, sino lo que existe es una separación de esferas de competencia. Sostiene Pastor Núñez que si el traspaso delegación de esfera se ha realizado en términos eficientes (elección de la persona adecuada, dotación de medios, incluida la información necesaria) eso genera un efecto de separación de esferas. Se le puede llamar así si se quiere una delegación sin deberes de vigilancia ni reacción: delegación, porque 
originariamente la responsabilidad es del socio, sin deberes de vigilancia ni reacción porque dicha "delegación" implica que la actividad del administrador queda separada de la del socio ${ }^{16}$.

El considerar que entre el socio fundador y el administrador existe una separación de esferas de competencia, implica que el socio no tiene el deber de organizar mecanismos, vigilancia sobre las conductas que realizan los administradores, ello en pro de verificar el adecuado cumplimiento de las funciones que ostenta el administrador, lo cual implica que de cometerse alguna ilícito penal que es atribuible al administrador, solo este asume las posibles consecuencias penales que acarrea su conducta (acción u omisión) no extendiéndose ello al socio fundador, debido a la separación de esferas competenciales existente entre ellos.

Así entonces, afirmar que la relación socios-administradores se rige por la estricta separación de esferas, significa que los conocimientos especiales no generan deberes de reacción: el socio que sabe y no reacciona (por ejemplo, pidiendo información al órgano de administración) no interviene en el delito del administrador, sino solamente infringirá, en su caso, un deber institucional llegando a cometer posiblemente delito alguno como el de omisión de socorro17.

\section{Toma postura}

Habiendo ya esbozado las tesis que se ensayan al tratar de brindar respuesta ante la posible o no responsabilidad penal del socio fundador frente a delitos cometidos desde la empresa por el órgano de administración, debemos indicar desde esta palestra que para dilucidar dicha problemática debemos enmarcar la conducta del socio fundador en dos momentos. El primero, referido al socio como fundador de la actividad empresarial, esto es, si por el hecho de dar origen a la actividad empresarial a este le corresponde o no una posición de garante originaria con base en la injerencia; y el segundo, el rol del socio fundador en el funcionamiento de la empresa, esto si cuando en el desarrollo de la actividad empresariales se cometen delitos por los administradores, los socios tienen o no alguna responsabilidad penal.

Desde esta palestra consideramos menester resaltar el momento en que se agota la creación de una empresa para dar cabida al momento del funcionamiento de esta. Siendo el hito que delimita dicha frontera el momento la constitución formal de la sociedad, la misma que no solo contiene el pacto social, sino también el estatuto, notándose que acorde a la normativa (Artículo $5^{\circ}$, Ley 26887), se exige que la constitución formal de la empresa se dé por escritura pública en la que se nombra

16 PASTOR NUÑEZ, Nuria. “ ¿Responsabilidad penal del socio por la criminalidad de la empresa? Reflexiones sobre la posibilidad de fundamentar una posición de garantía del socio". En Derecho Penal y Persona. Libro Homenaje a Jesús María Silva Sánchez. Lima: Ideas, 2019, p.931.

17 PASTOR NUÑEZ, op. cit., p. 931. 
los primeros administradores. Así, una vez constituida la empresa, se da inicio al funcionamiento de esta. Denotándose así la línea divisoria entre creación y funcionamiento de la empresa.

\section{i. Primer momento: Socio como fundador de la actividad empresarial}

La primera tesis referenciada parte del socio fundador de la empresa como el garante originario por la actividad riesgosa creada, es decir, atribuye el deber de garante basándose en la injerencia (actuar precedente), y así el socio delega en el órgano de administración estos deberes de velar por el adecuado manejo de la actividad riesgosa (que no afecte a tercero o que disminuya su afectación), destacándose con ello la figura de delegación, el socio fundador como delegante y el administrador como delegado, advirtiéndose además la existencia de una marcada jerarquía socio como superior y administrador como inferior, quien a su vez puede ser superior de alguien más al fungir como delegante de los deberes delegados por el socio. Empero, el socio pese a delegar aún posee deberes residuales, entre ellos; de vigilancia y control. Siendo factible así atribuírsele alguna responsabilidad penal ante la omisión de dichos deberes.

En referencia a los deberes residuales que ostentaría el socio fundador, exigiéndosele el adecuado cumplimiento de estos, desde esta palestra consideramos menester tener en cuenta lo que en la doctrina se denomina especialización funcional ${ }^{18}$, esto debido a que muchas veces, el socio fundador carece de los conocimientos que demanda la adecuada administración de la actividad empresarial, por ende, dicha labor la desarrollan los profesionales que sí poseen estos conocimientos, ello además en aras de poder obtener rentabilidad en la empresa, si en la administración de la misma se tiene a una persona no calificada para el cargo, es muy probable que se tenga pérdidas en vez de ganancias. En otras palabras, el socio no necesariamente tiene que saber de negocios, menos aún ser experto en el sector en el que desarrolla la actividad empresarial, por ello, esta tarea es del órgano de administración quien -en teoría- es conocedor de la materia. $\mathrm{Si}$, por ejemplo, un médico cirujano decide invertir en la creación de una refinería minera, es de suponer que carece de los conocimientos que exige el sector minero en cuanto una refinería se refiere y más aún sobre administración de empresas, por ello, es debidamente justificado que de esta labor se encarguen los administradores de la empresa para que estos lo desarrollen con grado de profesionalidad debido a su especialización en dichas aristas. Así entonces, salta la pregunta: ¿es posible que el socio fundador pueda cumplir adecuadamente los deberes residuales que ostenta -en especial vigilancia y control- si no posee los conocimientos que demanda el adecuado manejo de la actividad empresarial? Siguiendo con el ejemplo, ¿el médico cirujano podrá vigilar y controlar adecuadamente las

18 MARTÍNEZ MULERO, Víctor. El control de los administradores y la impugnación de sus acuerdos. Madrid: La ley 2005, p. 8. 
funciones del administrador de la refinería minera? La respuesta que podemos emitir es que es difícil -por no decir imposible-, ello debido al criterio de especialización. Al socio fundador no le es exigible que posea conocimientos sobre la actividad empresarial, mucho menos sobre la administración adecuada de esta, claro, haciendo hincapié que nos estamos refiriendo a grandes sociedades. Por este motivo, no consideramos que el socio fundador le sea exigible el cumplir adecuadamente los deberes residuales que ostenta, si se considera que este tiene el deber de garantía originario.

Sobre el socio fundador como garante originario debido a su actuar precedente al haber dado origen a la actividad empresarial, consideramos que debe tenerse en cuenta que la injerencia, como tal, implica reconocer una posición de garante con base en un actuar precedente. Ahora bien, sobre esta conducta precedente, Bacigalupo sostiene que es preciso que dicha conducta sea contraria al deber. En otras palabras, según lo referido por el aludido autor, el origen de la posición de garante queda limitada por el peligro permitido en el tráfico. La adecuación a derecho de la conducta precedente impide que de ella pueda deducirse un deber de garantía. Es decir, que la posición de garante por injerencia implica necesariamente que el autor haya creado un peligro adicional al permitido para la fuente que se encuentra bajo su dominio, para que su omisión sea equivalente a una acción, por lo que, si la conducta se encuentra enmarcada dentro del riesgo permitido, ello no da origen a una posición de garante ${ }^{19}$. Dicha concepción sobre la conducta precedente es compartida por Schünemann quien refiere que si la conducta precedente se mantiene dentro del riesgo permitido no fundamenta responsabilidad alguna ${ }^{20}$. En suma, siguiendo a Roxin, podemos afirmar que no existe posición de garante por injerencia si la acción previa se mantiene dentro del riesgo permitido excluyendo por lo tanto la imputación ${ }^{21}$. Así entonces, consideramos que el socio fundador que da origen a una actividad empresarial; el objeto social, como tal, actúa dentro del riesgo permitido. En otras palabras, para que una sociedad existe tiene que tener un objeto social (la actividad a la que se dedicará), siendo dicho objeto social necesariamente permitido por el ordenamiento jurídico, lo cual conlleva que sea una actividad que se encuentre dentro del riesgo permitido; por lo tanto, si es una actividad permitida por el derecho que se encuentra dentro del riesgo permitido, esta no genera una posición de garante, por lo que el socio fundador no tendría deberes de garante con base a su actuar precedente.

Habiendo ya asentado postura sobre los motivos por los cuales el socio fundador

19 BACIGALUPO, Enrique. Delitos impropios de omisión. Dykinson: Madrid, 2005, p. 203.

20 SCHÜNEMANN, Bernd. Fundamento y límites de los delitos de omisión impropia, trad. Cuello Contreras y Serrano González de Murillo. Marcial Pons: Madrid, 2009, p. 361.

21 ROXIN, Claus. Derecho penal, parte general, tomo II: especiales formas de aparición del delito, trad. Luzón Peña. Civitas, Madrid, 2014, p. 907. 
no sería garante por injerencia, debemos indicar que el socio como fundador de la actividad empresarial, limitándose solo a dar origen a la sociedad mas no llevando la gestión de la misma, debe estar limitado solo a la correcta constitución de la empresa en cuanto al objeto social (actividad a la que se dedicará) y el cumplimiento de las formalidades exigidas por la norma, específicamente la Ley General de Sociedades (Ley $N^{\circ}$ 26887). Así, ello guarda relación con aquella distinción entre los propietarios de la empresa (socios) y los gestores o controladores de esta (administradores). Son los administradores quienes por asunción deciden administrar la actividad empresarial, teniendo el deber que la misma se mantenga dentro de los márgenes del riesgo permitido, como también la adecuada organización de la actividad empresarial en sus distintos niveles, haciendo de uso para ello la delegación de deberes.

ii. Segundo momento: el socio fundador en el funcionamiento de la empresa

Aquí resulta necesario referimos a las esferas de competencia entre el socio y el órgano de administración, en la cual debido a dicha separación el socio fundador queda exento de responsabilidad penal. Bajo esta tesis, tanto el socio fundador como el administrador tienen su propio ámbito de responsabilidad, no existiendo en el socio fundador deberes residuales, habiendo ya analizado a que dicho criterio de imputación es factible en la existencia de estructuras horizontales, donde no hay una jerarquización de por medio.

Es de indicar que la especialización funcional allana el campo para argüir en este sentido, esto es, debido al desconocimiento del socio fundador de la actividad social y más aún de la misma administración empresarial, se requiere de profesionales de dicha materia, por ende, se alega que es de necesidad contar con las personas indicadas para ello. Así entonces, si el socio como garante originario delega en una persona idónea para ejercer la administración, ocurre la llamada separación de esferas, por lo tanto; de cometerse un delito desde la empresa por parte de los administradores, ello no incumbiría de alguna manera al socio fundador.

Ahora bien, desde esta palestra no consideramos de recibo que el socio fundador como garante delegue deberes al administrador y que entre estos exista una división de responsabilidades con base a las esferas de competencia (más allá que somos de la postura que el socio fundador no tiene posición de garante sobre la actividad empresarial), ello debido a que, para que pueda existir la delegación de deberes esta tiene que darse en una estructura vertical, donde el delegante es superior y el delegado inferior, lo que desnaturaliza la conceptualización de las esferas de competencia, ello debido a que estas se presentan en planos horizontales con base en la especialidad de cada uno, por lo que, no resulta admisible el referir que un delegante (superior), delega su inferior deberes y pese a ello no tiene 
deberes residuales dado que se está ante en el marco de las esferas de competencias. En suma, entre dos organizaciones unidas por un contexto de jerarquía no es admisible las esferas de competencia.

Así entonces, lo esbozado nos lleva a interrogarnos lo siguiente: si en el desarrollo de la actividad empresarial originada por el socio, el administrador comete algún delito desde la empresa, ¿cómo puede atribuírsele responsabilidad al socio si este no es garante de la actividad social, por ende, no tendría deberes residuales para con el administrador? Aquí es de tener en cuenta que la actividad empresarial en términos económicos va repercutir en el socio fundador, viéndose esto reflejado en pérdidas en cuando a su inversión o ganancias de la misma, por consiguiente: si el socio fundador tiene conocimiento que el órgano de administración de la empresa como parte de la actividad empresarial está cometiendo delitos, por ejemplo, vende productos cuya fecha de vencimiento expiró o está contaminando el medio ambiente, de lo cual el socio, por obvias razones, tendrá beneficios, este socio podría incurrir en un delito autónomo, diferente al que respondería el administrador, ya sea por ejemplo por receptación o- dependiendo del casolavado de activos, mas no tiene participación en el delito cometido por el administrador, como también podría responder por infringir un deber institucional, por ejemplo, no prestar auxilio o no avisar a la autoridad sobre la ingesta del producto vencido. 